\title{
ANALISA PERSEDIAAN BAHAN BAKU TEPUNG TERIGU DAN PERAMALAN HASIL PRODUKSI DI CV MUTIARA PRIMA BAKERY, DUSUN SABUK, GUNUNGSARI, JATISRONO, WONOGIRI, JAWA TENGAH
}

\author{
Yeri Hadi Winanto ${ }^{1}$, Rahmatul Ahya ${ }^{2}$, Ainur Komariah ${ }^{3}$ \\ ${ }^{1}$ Mahasiswa Program Studi Teknik Industri Univet Bantara Sukoharjo \\ ${ }^{2,3}$ Staf Pengajar Program studi Teknik Industri Univet Bantara Sukoharjo \\ Iyerihadi92@gmail.com, 22Rahmatulahya70@gmail.com,33ainurkomariah@yahoo.com
}

\begin{abstract}
ABSTRAK
Pada umumnya persediaan bahan baku dan peramalan hasil produksi di suatu perusahaan memang sangat penting, penelitian ini dilakukan di CV. Mutiara Prima Bakery, Dusun Sabuk, Gunungsari, Jatisrono, Wonogiri, Jawa Tengah, yang memproduksi roti besar dan roti kecil, dengan menggunakan bahan baku tepung terigu. Penelitian ini bertujuan untuk mengetahui persediaan bahan baku yang optimal untuk satu tahun terakhir dan mengetahui hasil peramalan produksi roti besar dan roti kecil untuk tahap berikutnya, pengumpulan data menggunakan metode wawancara. Metode yang digunakan untuk menghitung persediaan bahan baku adalah metode EOQ dan yang untuk menghitung peramalan produksi yaitu metode MA dan metode Exponential Smoothing. Dari hasil perhitungan CV. Mutiara Prima Bakery perlu melakukan pemesanan sebanyak 16 kali dalam setahun, dengan masing masing pemesanan sebanyak 92 sak tepung terigu. Total biaya persediaan yang optimal adalah sebesar Rp. 5,028,051.00 Kemudian untuk hasil peramalan produksi pada 2 minggu selanjutnya untuk roti besar sebesar 6,696.667 pcs dan untuk roti kecil sebesar 31,169.7 pcs. Jadi kesimpulannya CV. Mutiara Prima Bakery diharapkan menggunakan metode EOQ dalam menghitung persediaan bahan baku tepung terigu, dan memprediksi jumlah roti yang akan di produksi.
\end{abstract}

Kata kunci : analisis, persediaan, peramalan, EOQ

\section{PENDAHULUAN}

Sebuah perusahan memiliki tujuan utama yaitu memperoleh laba. dalam proses pencapaian tujuan tersebut akan dipengaruhi oleh berbagai faktor,salah satu faktor itu ialah kelancaran produksi. Pencapaian tujuan perusahaan akan menghadapi kendala tertentu sehingga perusahaan harus memiliki manajemen yang baik. Pada dasarnya manajemen yang baik memiliki fungsi yang sangat penting dalam perusahaan guna melakukan pemilihan keputusan serta sebagai kontrol dalam kegiatan perusahaan supaya berjalan secara efektif dan perusahaan mampu memperoleh laba yang optimal. Salah satu cara agar perusahaan mampu memperoleh laba yang optimal adalah menerapkan suatu kebijakan manajemen dengan memperhitungkan persediaan yang optimal. Dengan persediaan yang optimal perusahaan mampu menentukan seberapa besar persediaan bahan baku yang sesuai, sehingga tidak menimbulkan pemborosan biaya karena mampu menyeimbangkan kebutuhan bahan baku yang tidak terlau banyak maupun persediaan yang tidak terlalu sedikit (Taufiq, 2014). Karena persediaan yang besar juga tidak efisien karena biaya terlalu besar, sedangkan persediaan yang kecil beresiko tinggi akan menyebabkan terhentinya proses produksi maka manajemen persediaan menjadi kritis (Ma'arif dan Hendri Tanjung, 2003).

Mutiara Prima Bakery merupakan home industry yang berada di Dusun Sabuk rt 07 rw 04 Gunungsari, Jatisrono, Wonogiri, Jawa Tengah yang produk utamanya ialah roti manis, dan roti kecil. Bahan baku utama produk tersebut ialah tepung terigu, dimana untuk bahan baku tersebut harus selalu tersedia, supaya proses produksi terus berjalan. Disamping agar proses produksi terus berjalan, ketersediaan bahan baku harus tetap ada kapan saja. Berdasarkan hasil observasi lapangan permasalahan yang dialami CV Mutiara Prima Bakery adalah keterlambatan datangnya bahan baku karena stock di gudang sudah 
habis atau mengalami stock out, hal ini yang mengakibatkan proses produksi terhambat dan menimbulkan kemacetan. Maka dari itu, sangat diperlukan metode yang mampu mengendalikan persediaan bahan baku guna melancarkan proses produksi secara kontinyu.

Metode Economic Order Quantity (EOQ) merupakan metode yang diterapkan di dalam pengendalian persediaan bahan baku untuk menentukan kualitas dan kuantitas. Metode EOQ dapat menentukan jumlah pembelian bahan baku yang optimal setiap kali pemesanan dengan biaya minimal (Slamet, 2007:70). Tujuan dari penelitian ini adalah menentukan persediaan bahan baku yang optimal dan melakukan peramalan untuk proses produksi dengan menggunakan metode Economic Order Quantity (EOQ) di CV. Mutiara Prima Bakery. Sehingga diharapkan dengan menggunakan metode EOQ ini bahan baku dapat dikendalikan agar tidak menghambat proses produksi roti besar dan roti kecil.

Penelitian terdahulu yang berhubungan dengan pengendalian bahan baku adalah sepaerti yang dilakukan oleh Febri Eko Saputro (2017) yang meneliti tentang analisis pengendalian persediaan bahan baku untuk mencapai efisiensi biaya persediaan di PT. Kusumaputra Santoso menunjukkan adanya keterlambatan pasokan bahan baku cotton dan rayon yang mengakibatkan berhentinya proses produksi. Maka dalam pembelian bahan baku cotton dan rayon perlu di analisis menggunakan metode EOQ. Setelah dianalisis menggunakan EOQ, dapat disimpulkan bahwa untuk pembelian bahan baku cotton yang ekonomis adalah sebesar 186,369 Kg dengan frekuensi pembelian sebesar 62 kali dalam satu tahun, sedangkan untuk bahan baku rayon sebesar 105,144 Kg dengan frekuensi sebesar 41 kali dalam setahun. Jadi bisa disimpulkan maka sebaiknya PT. Kusumaputra Santoso menerapkan metode EOQ di dalam menentukan kuantitas pembelian bahan baku secara optimal sehingga dapat meminimalkan total biaya yang akan di keluarkan oleh perusahaan setiap tahunnya.

Selanjutnya penelitian yang dilakukan oleh Agil Saputro, Bambang Purwanggono (2016) yang meneliti tentang peramalan perencanaan produksi semen dengan metode exponential smoothing pada PT. Semen Indonesia menyatakan bahwa terjadi perbedaan signifikan over stock dan stock out. Dalam peramalan terdapat beberapa tahap yang harus dilakukan untuk mendapatkan peramalan yang baik. Setelah peramalan dilakukan analisis kesalahan yang paling kecil. Berdasarkan dari data historis, peramalan dilakukan dengan menggunakan metode exponential smoothing, hasil yang didapatkan sebesar 15048 (ribuan ton) untuk produksi semen tahun 2016 di PT. Semen Indonesia (Persero) Tbk.

\section{METODE PENELITIAN}

\section{Obyek Penelitian}

Penelitian dilakukan di CV Mutiara Prima Bakery, produk utama dari perushaan tersebut yaitu roti besar dan roti kecil, dalam mencari persediaan bahan baku tepung terigu, ada beberapa biaya-biaya yang harus dipenuhi. Biaya-biaya inilah yang nantinya akan digunakan untuk menghitung persediaan bahan baku tepung terigu supaya optimal dan mencari data produksi roti besar dan roti kecil tahun 2018 untuk meramalkan hasil produksi pada bulan januari 2019 di CV Mutiara Prima Bakery.

\section{Metode Pengumpulan Data}

Pengumpulan data pada penelitian ini dibagi menjadi dua, yaitu menggunakna teknik wawancara dan studi literatur.

a. Wawancara

Wawancara dilakukan secra langsung dengan pemilik CV. Mutiara Prima Bakery. Data-data yang dibutuhkan dalam wawancara ini adalah meliputi bahan produksi, biaya produksi, berapa jumlah produksi setiap periode.

b. Studi literatur

Studi literaur adalah cara yang dipakai untuk menghimpun data-data dari sumber yang berhubungan dengan topik dalam penelitian, yaitu dengan melakukan studi 
literatur pada buku-buku atau artikel yang membahas tentang metode yang digunakan untuk menghitung persediaan bahan baku dan metode peramalan produksi.

\section{Menentukan Economic Order Quantity (EOQ)}

EOQ (Economic Order Quantity) adalah jumlah pemesanan bahan baku yang dapatmeminimumkan total biaya persediaan, dan mengoptimalkan persediaan. Untuk mengetahui berapa total bahan baku yang harus dibeli dalam setiap kali pembelian untuk memenuhi kebutuhan selama satu periode pemesanan. (Yamit, 1999). Kebanyakan teori tentang persediaan mengatakan bahwa model EOQ mudah untuk diterapkan apabila asumsi dasar dalam EOQ dipenuhi, yaitu:

a. Permintaan produk yang tetap, seragam dan diketahui.

b. Harga per unit produk adalah sama.

c. Biaya penyimpanan satu unit per tahun adalah konstan.

d. Biaya pemesanan per pemesanan adalah konstan.

e. waktu antara pesanan dilakukan dan barang-barang diterima adalah konstan.

f. Tidak terjadi kekurangan barang atau back order.

\section{Menentukan Metode Peramalan}

Menentukan metode peramalan dengan mengetahui kriteria data yang tersedia, dengan itu penelitian dapat di lakukan dengan mengamati pola data yang ada di perusahaan tersebut, kemudian menetapkan metode apa saja yang dipakai. Perhitungan pun dilakukan dengan menggunakan metode yang ditentukan. Setelah perhitungan dilakukan maka hasil dari perhitungan kesalahan peramalan dibandingkan. Kemudian hasil peramalan dengan nilai error terkecil dipilih sebagai peramalan.

\section{HASIL PENELITIAN DAN PEMBAHASAN}

\section{Pengumpulan Data}

Berikut ini merupakan data pemesanan bahan baku tepung terigu pada CV Mutiara Prima Produksi dengan memesan dari Distributor Slamet Jaya Ponorogo pada tahun 2018. Data pemesanan tepung terigu dalam 1 bulan ada 2 periode pemesanan bahan baku. Data tersebut dapat dilihat pada tabel 1.

Tabel 1. Data Pemesanan Tepung Terigu Tahun 2018

\begin{tabular}{|c|c|c|c|}
\hline Periode & $\begin{array}{c}\Sigma \text { Pemesanan } \\
(\text { sak })\end{array}$ & $\begin{array}{c}\Sigma \text { Kebutuhan } \\
\text { Bahan (sak) }\end{array}$ & $\begin{array}{c}\Sigma \text { Kekurangan } \\
\text { Bahan (sak) }\end{array}$ \\
\hline 1 & 60 & 64 & 4 \\
\hline 2 & 65 & 65 & 0 \\
\hline 3 & 55 & 60 & 5 \\
\hline 4 & 58 & 60 & 2 \\
\hline 5 & 62 & 65 & 3 \\
\hline 6 & 65 & 65 & 2 \\
\hline 7 & 52 & 54 & 1 \\
\hline 8 & 64 & 65 & 0 \\
\hline 9 & 65 & 65 & 3 \\
\hline 10 & 60 & 60 & 1 \\
\hline 11 & 55 & 58 & \\
\hline 12 & 54 & 55 & 0 \\
\hline
\end{tabular}


Tabel 1. Data Pemesanan Tepung Terigu Tahun 2018

\begin{tabular}{|c|c|c|c|}
\hline Periode & $\begin{array}{c}\Sigma \text { Pemesanan } \\
\text { (sak) }\end{array}$ & $\begin{array}{c}\Sigma \text { Kebutuhan } \\
\text { Bahan (sak) }\end{array}$ & $\begin{array}{c}\Sigma \text { Kekurangan } \\
\text { Bahan (sak) }\end{array}$ \\
\hline 13 & 63 & 65 & 2 \\
\hline 14 & 63 & 63 & 0 \\
\hline 15 & 57 & 58 & 1 \\
\hline 16 & 52 & 55 & 3 \\
\hline 17 & 64 & 64 & 0 \\
\hline 18 & 60 & 60 & 0 \\
\hline 19 & 65 & 65 & 0 \\
\hline 20 & 58 & 62 & 4 \\
\hline 21 & 55 & 58 & 3 \\
\hline 22 & 59 & 60 & 1 \\
\hline 23 & 60 & 65 & 5 \\
24 & 61 & 65 & 4 \\
\hline Total & 1,432 & 1,476 & \\
\hline
\end{tabular}

\section{Biaya Pemesanan Bahan Baku}

Biaya yang dikeluarkan oleh perusahaan dalam melakukan pemesanan antara pihak $\mathrm{CV}$ dengan supplier. Biaya pemesanan bahan baku yang harus dikeluarkan oleh CV Mutiara Prima Bakery dapat dilihat pada Tabel 2.

Tabel 2. Biaya pemesanan

\begin{tabular}{|c|l|r|}
\hline No & Jenis biaya & \multicolumn{1}{c|}{ Biaya $(\mathrm{Rp})$} \\
\hline 1 & Telp & 54,300 \\
\hline 2 & Ekspedisi & $2,400,000$ \\
\hline 3 & Administrasi & $1,440,000$ \\
\hline \multicolumn{2}{|c|}{ Jumlah } & $3,894,300$ \\
\hline
\end{tabular}

\section{Biaya Penyimpanan Bahan Baku}

Biaya yang dikeluarkan oleh perusahaan karena melakukan penyimpanan bahan baku dalam jangka waktu tertentu. Biaya penyimpanan bahan baku yang ditanggung oleh CV Mutiara Prima Bakery dapat dilihat pada Tabel 3 berikut.

Tabel 3. Biaya penyimpanan

\begin{tabular}{|c|c|c|}
\hline No & Jenis biaya & Biaya (Rp) \\
\hline 1 & Listrik & 980,000 \\
\hline 2 & Asuransi & 240,000 \\
\hline 3 & Karyawan & $18,000,000$ \\
\hline \multicolumn{2}{|r|}{ Jumlah } & $19,220,000$ \\
\hline
\end{tabular}

\section{Menghitung Rata-rata Pemesanan}

Menentuakan rata-rata pemesanan bahan baku tepung terigu dalam setahun. Ini berguna unruk mengetahui nilai $\mathrm{Q}$ pada rumus $\mathrm{EOQ}$, adapun rumusnya sebagai berikut:

$$
\mathrm{Q}=\frac{\text { Total pemesanan }}{\text { Frekuensi pemesanan }}
$$




$$
\begin{aligned}
& =\frac{1432}{24} \\
& =59,5 \mathrm{sak}
\end{aligned}
$$

Jadi jumlah pembelian bahan baku di CV Mutiara Prima Bakery dalam 1 kali pemesanan sebesar 59,5 sak.

\section{Pemesanan ekonomis}

Pemesanan ekonomis adalah pemesanan bahan baku yang dihitung menggunakan rumus EOQ, dengan memasukkan sejumlah data seperti, D yaitu total kebutuhan dalam setahun sebesar 1432, S yaitu rata-rata biaya pemesanan untuk sekali pesan sebesar $162,262.5$, Hc yaitu persentase biaya penyimpanan dari harga 1 sak tepung terigu sebesar 54,400

$$
\begin{aligned}
& \mathrm{EOQ}=\sqrt{\frac{2 D S}{H c}} \\
& \mathrm{EOQ}=\sqrt{\frac{2(1432)(162,262.5}{160,000 \times 0.34}} \\
& \mathrm{EOQ}=\sqrt{\frac{2(1432)(162,262.5}{54,400}} \\
& \mathrm{EOQ}=\sqrt{8,542.64338} \\
& \mathrm{EOQ}=92.4
\end{aligned}
$$

Jadi jumlah pembelian bahan baku yang ekonomis adalah sebesar 92 sak untuk sekali pesan. Setelah diketahui pembelian bahan baku yang ekonomis, selanjutnya adalah menghitung frekuensi pemesanan.

$$
\begin{aligned}
& \mathrm{F}=\frac{D}{Q *} \\
& \mathrm{~F}=\frac{1432}{92} \\
& \mathrm{~F}=15,5 \\
& \mathrm{~F}=16 \text { kali }
\end{aligned}
$$
1 tahun.

Jadi, frekuensi pemesanan bahan baku dilakukan sebanyak 16 kali pemesanan dalam

\section{Total Inventory Cost (TIC)}

TIC perusahaan memasukkan sejumlah data seperti, Q Yaitu rata rata pemesanan untuk sekali pesan menurut kebijakan perusahaan sebesar 59.5, D yaitu total kebutuhan dalam setahun sebesar 1432, S yaitu rata-rata biaya pemesanan untuk sekali pesan sebesar $162,262.5$, Hc yaitu persentase biaya penyimpanan dari harga 1 sak tepung terigu sebesar 54,400

$$
\begin{aligned}
\text { TIC } & =\frac{D}{Q} S+\frac{Q}{2} H c \\
& =\left(\frac{1432}{59.5} \cdot 162,262.5\right)+\left(\frac{59.5}{2} \cdot 54,400\right) \\
& =3,894,300+1,618,400 \\
& =5,512,700
\end{aligned}
$$

TIC EOQ adalah penghitungan total biaya penyimpanan bahan baku tepung terigu yang harus dibayar perusahaan dalam setahun yaitu dengan menggunakan rumus TIC EOQ dengan memasukkan sejumlah data seperti, Q Yaitu rata rata pemesanan untuk sekali pesan jika menggunakan rumus EOQ sebesar 92, D yaitu total kebutuhan dalam setahun sebesar 1432, S yaitu rata-rata biaya pemesanan untuk sekali pesan sebesar 
162,262.5, Hc yaitu persentase biaya penyimpanan dari harga 1 sak tepung terigu sebesar 54,400

$$
\begin{aligned}
\text { TIC } & =\frac{D}{Q} S+\frac{Q}{2} H c \\
& =\left(\frac{1432}{92} \cdot 162,262 \cdot 5\right)+\left(\frac{92}{2} \cdot 54,400\right) \\
& =2,525,651+2,502,400 \\
& =5,028,051
\end{aligned}
$$

Dari perhitungan tersebut didapat hasil penghematan Total Inventory Cost sebesar Rp. 484,649 atau $8.79 \%$

\section{Safety stock}

Dalam menentukan persediaan pengaman, rata rata bahan baku dibutuhkan guna membandingkan pemakaian bahan baku yang menyimpang. Sebelum menghitung Persediaan pengaman (safety stock), terlebih dahulu mencari standar deviasi untuk mengetahui besar penyimpanan pemesanan bahan baku di CV Mutiara Prima Bakery. Menentukan standar deviasi memerlukan data persediaan bahan baku, adapun perhitungannya pada Tabel 4.

Tabel 4. Perhitungan Standar Deviasi

\begin{tabular}{|c|c|c|c|c|}
\hline Periode & $\begin{array}{c}\Sigma \\
\text { pemesanan }\end{array}$ & $X$ & $(X-\overline{\mathrm{X}})$ & $(X-\overline{\mathrm{X}})^{2}$ \\
\hline 1 & 60 & 59,5 & 0,5 & 0.25 \\
\hline 2 & 65 & 59,5 & 5,5 & 30.25 \\
\hline 3 & 55 & 59,5 & $-4,5$ & 20.25 \\
\hline 4 & 58 & 59,5 & $-1,5$ & 2.25 \\
\hline 5 & 62 & 59,5 & 2,5 & 6.25 \\
\hline 6 & 65 & 59,5 & 5,5 & 30.25 \\
\hline 7 & 52 & 59,5 & $-7,5$ & 56.25 \\
\hline 8 & 64 & 59,5 & 4,5 & 20.25 \\
\hline 9 & 65 & 59,5 & 5,5 & 30.25 \\
\hline 10 & 60 & 59,5 & 0,5 & 0.25 \\
\hline 11 & 55 & 59,5 & $-4,5$ & 20.25 \\
\hline 12 & 54 & 59,5 & $-5,5$ & 30.25 \\
\hline 13 & 63 & 59,5 & 3,5 & 12.25 \\
\hline 14 & 63 & 59,5 & 3,5 & 12.25 \\
\hline 15 & 57 & 59,5 & -2.5 & 6.25 \\
\hline 16 & 52 & 59,5 & $-7,5$ & 56.25 \\
\hline 17 & 64 & 59,5 & 4,5 & 20.25 \\
\hline 18 & 60 & 59,5 & 0,5 & 0.25 \\
\hline 19 & 65 & 59,5 & 5,5 & 30.25 \\
\hline 20 & 58 & 59,5 & $-1,5$ & 2.25 \\
\hline 21 & 55 & 59,5 & $-4,5$ & 20.25 \\
\hline 22 & 59 & 59,5 & $-0,5$ & 0.25 \\
\hline 23 & 60 & 59,5 & 0,5 & 0.25 \\
\hline 24 & 61 & 59,5 & 1,5 & 2.25 \\
\hline & 1432 & & & 410 \\
\hline & & & & \\
\hline
\end{tabular}


Menghitung standar deviasi dengan rumus sebagai berikut ini:

$$
\begin{aligned}
\mathrm{SD} & =\sqrt{\frac{\sum(X-\overline{\mathrm{X}})^{2}}{n}} \\
& =\sqrt{\frac{410}{24}} \\
& =\sqrt{17,083} \\
& =4,13
\end{aligned}
$$

Dari perhitungan sebelumnya diketahui nilai SD sebesar 4,13, selanjutnya menentukan nilai standar penyimpangan CV Mutiara Prima Bakery sebesar 5\% sehingga diperoleh $\mathrm{Z}$ pada tabel standar deviasi sebesar 1,65 maka perhitungannya sebagai berikut:

Safety Stock $=\mathrm{SD} \times \mathrm{Z}$

$$
\begin{aligned}
& =4,13 \times 1,65 \\
& =6,81 \\
& =7 \mathrm{Sak}
\end{aligned}
$$

Jadi persediaan pengaman yang di haruskan oleh CV Mutiara Prima Bakery adalah sebesar $7 \mathrm{sak}$

\section{Reader point}

CV Mutiara Prima Bakery memerlukan waktu tunggu untuk menunggu pesanan bahan baku tepung terigu selama 2 hari $(L)$, dengan asumsi jumlah hari kerja 286 hari $(t)$, dalam 1 tahun perusahaan memerlukan 1432 sak tepung terigu $(D)$ dan untuk bahan baku pengaman (SS) adalah sebesar 7 sak. Sebelum menghitung ROP (Re Order Point), terlebih dahulu mencari tingkat penggunaan bahan baku per hari $(d)$, adapun perhitungannya sebagai berikut:

$$
\begin{aligned}
\mathrm{d} & =\frac{D}{t} \\
& =\frac{1432}{286} \\
& =5 \mathrm{sak}
\end{aligned}
$$

Jadi untuk titik pemesanan kembali (ROP) adalah:

$$
\begin{aligned}
\mathrm{ROP} & =(d \times L)+S S \\
& =(5 \times 2)+7 \\
& =17 \mathrm{sak}
\end{aligned}
$$

\section{Peramalan Hasil Produksi}

Dalam menentukan peramalan produksi roti besar dan roti kecil. Hal yang perlu diutamakan adalah mengetahui tingkat penjualan kedua jenis roti tersebut setelah diketahui tingkat penjualan per periode, kemudian yang pertama adalah menggambarkan pola data penjualan roti besar dan roti kecil tersebut kesebuah grafik, hal ini bertujuan untuk menentukan metode apa yang akan digunakan dalam peramalan. Berikut ini merupakan tabel data hasil penjualan roti besar dan roti kecil di CV Mutiara Prima Bakery pada Tabel 6.

Tabel 6. Hasil Penjualan Roti Besar dan Roti Kecil Tahun 2018 per 2 Minggu

\begin{tabular}{|c|c|c|}
\hline Periode & $\begin{array}{c}\text { Hasil Penjualan Roti Kecil } \\
(\mathrm{pcs})\end{array}$ & $\begin{array}{c}\text { Hasil Penjualan Roti Besar } \\
(\mathrm{pcs})\end{array}$ \\
\hline 1 & 28720 & 7710 \\
\hline 2 & 31160 & 7160 \\
\hline 3 & 31100 & 5840 \\
\hline 4 & 28710 & 6590 \\
\hline
\end{tabular}


Tabel 6. Hasil Penjualan Roti Besar dan Roti Kecil Tahun 2018 per 2 Minggu (lanjutan)

\begin{tabular}{|c|c|c|}
\hline Periode & $\begin{array}{l}\text { Hasil Penjualan Roti Kecil } \\
\text { (pcs) }\end{array}$ & $\begin{array}{l}\text { Hasil Penjualan Roti Besar } \\
\text { (pcs) }\end{array}$ \\
\hline 5 & 31200 & 8320 \\
\hline 6 & 31080 & 6450 \\
\hline 7 & 26400 & 7200 \\
\hline 8 & 26350 & 7160 \\
\hline 9 & 31120 & 7100 \\
\hline 10 & 35900 & 6540 \\
\hline 11 & 31100 & 5360 \\
\hline 12 & 31150 & 5900 \\
\hline 13 & 31000 & 7050 \\
\hline 14 & 26400 & 8300 \\
\hline 15 & 28700 & 6510 \\
\hline 16 & 26260 & 5890 \\
\hline 17 & 31190 & 6500 \\
\hline 18 & 38050 & 6490 \\
\hline 19 & 27800 & 7120 \\
\hline 20 & 28800 & 7650 \\
\hline 21 & 30900 & 5890 \\
\hline 22 & 32900 & 5840 \\
\hline 23 & 31100 & 6560 \\
\hline 24 & 31030 & 7120 \\
\hline
\end{tabular}

Pola menunjukkan jumlah hasil penjualan setiap 2 minggu sekali adalah berfluktuasi, dan tidak menunjukkan nilai trend positif.Jadi dapat disimpulkan metode yang akan dipilih yaitu metode MA (Moving Averages) dan metode Exponential Smoothing, tahap kedua adalah menghitung data peramalan penjualan dengan menggunakan metode MA (Moving Averages) dan metode Exponential Smoothing,setelah hasil dari peramalan kedua metode didapatkan, kemudian dilakukan analisis kesalahan, dengan cara memilih forecast mana yang memiliki nilai error paling kecil dari kedua metode tersebut, selanjutnya hasil forecast yang memiliki nilai error paling kecil tersebut, digunakan sebagai acuan untuk produsi 2 minggu pertama pada Bulan Januari 2019.

a. Perhitungan menggunakan metode MA (Moving Averages)

Metode MA adalah metode yang bertujuan menyetarakan data hasil produksi dengan hasil peramalan, disini perhitungannya menggunakan rata-rata $3 \mathrm{MA}, 5$ MA, 6 MA, ini digunakan supaya nilai peramalan dari metode MA dapat mendekati nilai aktual.

b. Perhitungan menggunakan metode Exponential Smoothing

Metode Exponential Smoothing adalah metode peramalan yang mengedepankan penghalusan data dengan mendekatkan data peramalan dengan data aktual. Peramalan ini menggunakan nilai konstanta sebagai ketetapan dengan melakukan percobaan beberapa kali, nilai konstanta/alpha yang ditetapkan adalah $0<\alpha<1$, maka dalam menentukan nilai $\alpha$, penulis melakukan percobaan dengan memilih beberapa nilai $\alpha$ antara lain $\alpha=0,2, \alpha=0,4, \alpha=0,6$ dan $\alpha$ yang terbaik. 
Dari hasil kualifikasi masing-masing metode, selanjutnya hasil dari pemilihan kedua metode tersebut dibandingkan untuk menentukan hasil peramalan produksi yang terbaik untuk 2 minggu pertama pada Bulan Januari 2019.

Tabel 8. Perbandingan Metode MA dan Exponential Smoothing untuk Roti Besar

\begin{tabular}{|c|c|c|}
\hline & $\begin{array}{c}\text { Metode MA } \\
\text { Terbaik }\end{array}$ & $\begin{array}{c}\text { Metode Exponential } \\
\text { Smoothing Terbaik }\end{array}$ \\
\hline $\begin{array}{c}\text { Analisa } \\
\text { kesalahan }\end{array}$ & $6 \mathrm{MA}$ & $\alpha=0,21$ \\
\hline Forecast & $6,696.67$ & $6,650.08$ \\
\hline CFE & $-1,206$ & -5047.234 \\
\hline
\end{tabular}

Tabel 8. Perbandingan Metode MA dan Exponential Smoothing untuk Roti Besar

\begin{tabular}{|c|c|c|}
\hline & $\begin{array}{c}\text { Metode MA } \\
\text { Terbaik }\end{array}$ & $\begin{array}{c}\text { Metode Exponential } \\
\text { Smoothing Terbaik }\end{array}$ \\
\hline MAD & 577.0371 & 703.8166 \\
\hline MSE & 582704 & 759454.4 \\
\hline MAPE & 8.883373 & 10.79931 \\
\hline Tracking Signal & -2.091141 & -7.171235 \\
\hline
\end{tabular}

Tabel 9. Perbandingan Metode MA dan Exponential Smoothing untuk Roti Kecil

\begin{tabular}{|c|c|c|}
\hline & $\begin{array}{c}\text { Metode MA } \\
\text { Terbaik }\end{array}$ & $\begin{array}{c}\text { Metode Exponential } \\
\text { Smoothing Terbaik }\end{array}$ \\
\hline $\begin{array}{c}\text { Analisa } \\
\text { kesalahan }\end{array}$ & $5 \mathrm{MA}$ & $\alpha=0,26$ \\
\hline Forecast & 30,946 & $31,169.70$ \\
\hline CFE & 2,734 & $8,880.84$ \\
\hline MAD & 2639.263 & $2,339.31$ \\
\hline MSE & $1.25 \mathrm{E}+12$ & $1.00 \mathrm{E}+13$ \\
\hline MAPE & 8.640836 & 7.62886 \\
\hline Tracking Signal & 1.035895 & 3.796065 \\
\hline
\end{tabular}

Selisih hasil peramalan roti besar dari kedua metode tersebut hasilnya cukup kecil, tapi jika membandingkan dari nilai analisa kesalahan, metode 6 MA memiliki kesalahan lebih kecil dibandingkan metode Exponential Smoothing yaitu pada nilai CFE, MA, MSE, MAPE, dan Tracking signal. Jadi hasil peramalan yang menggunakan metode 6 MA yang layak dijadikan hasil akhir dengan nilai forecast sebesar 6,696.667 Pcs.

Kemudian untuk peramalan produksi roti kecil, selisih hasil peramalan yang didapat dari kedua metode tersebut juga cukup kecil, akan tetapi menurut hasil perbandingan analisa kesalahan, metode Exponential Smoothing alpha 0,26 yang memiliki nilai analisa kesalahan lebih kecil yaitu pada nilai MAD, MSE, dan MAPE, dan lebih besar pada nilai CFE dan Tracking signal, walaupun begitu hasil peramalan metode Exponential Smoothing alpha 0,26 lah yang menjadi hasil akhir dengan nilai forecast sebesar 31,169.7. 


\section{KESIMPULAN DAN SARAN}

\section{Kesimpulan}

Dari pembahasan yang telah di paparkan, maka dapat diambil kesimpulan, yaitu:

a. Untuk persediaan bahan baku tepung terigu pada tahun 2018 didapat total biaya persediaan bahan baku tepung terigu menurut kebijakan perusahaan sebesar Rp. $5,512,700.00$, dengan frekuensi pemesanan sebanyak 24 kali dalam setahun, dengan rata-rata jumlah bahan bakunya sebanyak 59,5 sak dalam 1 kali pemesanan. Tetapi jika menggunakan metode EOQ, total biaya persediaan bahan baku tepung terigu yang diperoleh sebesar Rp. 5,028,051.00 lebih murah dibandingkan menggunakan kebijakan perusahaan, dengan frekuensi pemesanannya sebanyak 16 kali dalam setahun. Jika dalam 1 tahun asumsi dari perusahaan ada 48 minggu, maka untuk pemesanannya yaitu 48 minggu dibagi 16 kali pemesanan maka diperoleh jadwal pemesanannya setiap 3 minggu sekali, dengan rata-rata pemesanan 92 sak dalam 1 kali pesan. Jadi CV Mutiara Prima Bakery diharapkan menggunakan metode EOQ untuk menghitung persediaan bahan baku supaya dapat menghemat biaya pengeluaran.

b. Hasil dari peramalan produksi roti besar dan roti kecil yang menggunakan metode MA dan Exponential Smoothing, pada 2 minggu pertama Bulan Januari 2019 adalah sebesar 6,696.667 pcs untuk roti besar, dan 31,169.7 pcs untuk roti kecil.

\section{Saran}

Berdasarkan hasil analisa pada pembahasan, saran yang dapat diberikan adalah:

a. Bagi peneliti yang akan melakukan penelitian yang sama, diharapkan mempertimbangkan beberapa metode yang lain, yang berbeda, supaya ada penyempurnaan dalam mendapatkan hasil yang lebih baik.

b. Dengan hasil yang diperoleh dari pembahasan, sebaiknya perusahaan melakukan persediaan bahan baku dengan metode EOQ dan meramalkan hasil produksi, guna meminimalkan biaya pengeluaran.

\section{DAFTAR PUSTAKA}

Achmad, Slamet. (2007). Penggangaran Perencanaan dan Pengendalian Usaha. Semarang: UNNES PRESS.

Ahyari, Agus, (1999).Mananajemen Produksi Perencanaan Sistem Produksi. Edisi 4.Yogyakarta: BPFE.

Bambang Purwanggono, Agil Saputro. 2016. Peramalan Perencanaan Produksi Semen dengan Metode Exponential Smoothing pada PT. Semen Indonesia. Semarang: Universitas Diponegoro Program Studi Teknik Industri.

Nasution, Arman Hakim. 2003. Perencanaandan Pengendalian Produksi. Edisi Pertama. Surabaya: Guna Widya.

Saputro, Eko Febri. 2017. Analisis Pengendalian Persediaan Bahan Baku Untuk Mencapai Efisiensi Biaya Persediaan. Sukoharjo: TI UNIVET

Syamsul Ma'arif dan Hendri Tanjung. 2003. Manajemen Operasi. Edisi Pertama, PT. Grasindo, Jakarta

Taufiq, A. \& Slamet, A. 2014. Pengendalian Persediaan Bahan Baku Dengan Metode Economic Order Quantity (EOQ) pada Salsa Bakery Jepara. Management Analysis Journal. 3

Yamit, Zulian. 1999. Manajemen Persediaan. Yogyakarta: Ekonosian FE UI. 